\title{
Do Couples Bargain over Fertility?
}

\author{
Timo Hener \\ Ifo Institute
}

\begin{abstract}
Neoclassical theory predicts that opportunity costs depress fertility. This view may be oversimplifying. In a household bargaining framework, wages also affect the intra-household distribution and, thus, the investment in household public goods like children. We demonstrate in a standard collective model the interplay of child preferences with opportunity cost and bargaining power effects. Theory provides the seemingly counter-intuitive result that, under certain conditions, female wages can increase fertility. In the empirical analysis, we present results consistent with the prediction that for couples with discordant child preferences bargaining power affects fertility choices.*
\end{abstract}

*Keywords: fertility; child preferences; intra-household allocation; household bargaining. JEL codes: D01, D13, J13. 


\section{Introduction}

The traditional approach to studying the choices of multi-person households assumes that families behave as if they were single decision-making units (SAMUELSON [1956], BECKER [1973]) . Although this unitary setting is convenient and has produced important insights, it neither characterizes individuals by their own preferences, nor does it capture the intuitive idea that household choices are the result of a bargaining process between family members. The collective model of household behavior (CHIAPPORI [1988, 1992]) overcomes these disadvantages and predicts that intra-household allocations in private goods reflect differences in preferences and "bargaining power" of individuals. Extended versions of the collective models also include the consumption of public goods (BLUNDELL ET AL. [2005], Chiappori and Ekeland [2006], Donni [2009]). It has been shown that the underlying preferences and Pareto weights can be identified when each agent can be excluded from the consumption of at least one commodity (CHIAPPORI and EkELAND [2009]) . This paper uses a new framework to identify a collective model for the household public good children using reported preferences about having children.

We begin with presenting a simple model of household bargaining to show how decisions about the household public good children are related to the intra-household allocation of bargaining power and individual preferences. Wages influence at the same time the shadow price of children, the consumption possibilities and bargaining power, which yields opposing effects on fertility. What becomes explicit in the model is that while bargaining power is without effect if partners' individual child preferences are alike, it becomes crucial if there is a conflict about the public good level. In the next step, our theory guides an empirical estimation that investigates the main propositions of the model-household bargaining power matters for the fertility decision if, and only if, the partners' child preferences are discordant.

The basic framework adopted builds on the collective bargaining model (CHIAPPORI $[1988,1992]) .^{1}$ Two agents in a household decide over private consumption, leisure and the number of children. The key feature of the collective approach is that decision outcomes are necessarily Pareto efficient. This is achieved by maximizing a weighted household welfare function with relative wages as the distribution factor ${ }^{2}$. Conventional wisdom suggests that female wages increase the opportunity costs of child rearing and have adverse effects on

\footnotetext{
${ }^{1}$ For other influential approaches to the bargaining framework see MANSER and Brown [1980] and MCElRoY and Horney [1981] .

${ }^{2}$ See Browning Et AL. [2006] and Browning ET AL. [1994] for discussions of the terminology concerning the weighting factors.
} 
fertility. ${ }^{3}$ However, they may also positively affect the woman's bargaining power. A key insight of the paper is that, even under the extreme assumption that women are the only provider of child rearing time, female relative wages can increase fertility. This seemingly counter-intuitive result comes about by the interplay of individual preferences and intrahousehold bargaining. We split the effect of female relative wages into a relative cost and a bargaining power effect to illustrate our findings. The relative cost effect is always negative, whereas the bargaining power effect can take on both signs. It becomes positive if the female preferences for the household public good, children, is stronger than her partner's and negative vice versa. Her bargaining power increases with her relative wage, counteracting the negative relative cost effect if her preferences are stronger or exacerbating the negative effect if her preferences are weaker than her partner's. Under certain circumstances the positive bargaining power effect can overcompensate the negative relative cost effect such that higher female wages increase fertility.

The distinction between relative cost and bargaining power effects suggests a test for the prediction of collective bargaining that can be inferred from data. We apply the world's second longest running household survey data - the German Socio-Economic Panel SOEPwhich is similar to the Panel Study of Income Dynamics (PSID) in the United States and the British Household Panel Survey (BHPS) and the only large-scale data source that also carries information on child preferences. The data contain a survey question about the importance of having children which does not immediately qualify as preference data, but, as we will show, has good predictive power for completed fertility and can serve as a proxy for child preferences. Two different estimation equations (one with a continuous difference of child preferences and one with dummy variables indicating stronger child preferences of the female respectively the male partner) reveal exactly the relationship of bargaining power (proxied by relative wages within couples) and child preferences predicted by the theory: positive or negative bargaining power effects conditional on the preference relation. Our empirical results are consistent with the theory and they are robust to a number of different specifications.

This paper complements a larger empirical literature on private goods consumption as household bargaining outcomes. Browning ET AL. [1994] and LundBERG ET AL. [1997] show that sex-specific clothes expenditure is affected by the intra-household allocation of resources. In fact, LUNDBERG ET AL. [1997] also show that bargaining power of women tends to ramp up expenditure for child clothes. ERmisch and Pronzato [2008] look at

\footnotetext{
${ }^{3}$ This holds if child rearing time cannot be bought in the market and the income effect of a wage increase does not overcompensate the higher price of time.
} 
child support from fathers who have new partners who are not the mothers of their children. They find that income shares of the fathers increase the share of resources devoted to and the probability of child support. Using Brazilian data THOMAs [1990] shows that non-wage income allocation between parents affects family health. In a similar fashion, PHIPPS and BuRTON [1998] reject the hypothesis that partners' incomes are equally spent on a number of consumption goods. For the case of a developing country, HADDAD and HoDDINOT [1995] find that the female income share positively affects the share of food expenditure in total consumption. Despite the vast evidence consistent with bargaining models the empirical literature remained relatively silent about household public goods. An exception is DonNI [2009] who tests the collective model using two public goods from the U.S. Consumer Expenditure Survey. Among the few studies concerned with fertility, Schultz [1990] finds without the use of preference data that fertility is responsive to female non-earned income, concluding that this result is inconsistent with the unitary model. The only study to our knowledge that uses explicit child preference data in this area is RAsul [2008] . He uses Malaysian data to infer whether couples can commit to the fertility decisions modeled in a bargaining framework and concludes that commitment is not kept up. He also finds, consistent with our results, that land inheritance of the male spouse is associated with a larger effect of his and a lower effect of her child preferences on the couple's fertility.

The greatest challenge in identifying causal effects of bargaining power is to find plausibly exogenous factors influencing intra-household allocation of bargaining power. A few studies achieving this infer from data that bargaining power matters and explain their findings by sex-specific preferences without using explicit preference data. QIAN [2008] establishes causality by exploiting geographic slope that determines the suitability of soil for cultivating tea and women's comparative advantage at plucking tea leaves in rural China. She finds that female bargaining power causally influences children's education and girls' survival rates. Duflo [2003] exploits a South African pension reform and finds that having a female as the recipient leads to positive effects on girls' height and weight what is probably the cause of better nutrition. Similarly aiming at sex-specific preferences, Thomas [1994] investigates the relationship of parental resource allocation and child height using fixed-effects methods that control for time-invariant unobserved family heterogeneity. He finds that female bargaining power is positively associated with girls' height and correspondingly male bargaining power with boys' height. This literature ${ }^{4}$ shows that the empirical results are robust to methods that require a causal effect of bargaining power on household decisions under reasonably weak assumptions. As we lack plausible exogenous variation that can be linked to our data,

\footnotetext{
${ }^{4}$ LUNDBERG ET AL. [1997] should also be mentioned in this context as they exploit a policy reform.
} 
we will only remotely touch on issues of causality in this paper and discuss some unreported results obtained from panel data methods including fixed-effects estimation that eliminates individual time-invariant unobserved confounding factors.

For future research, methods for investigating household decisions about fertility can be carried over to other household public goods by using suitable preference data. For policy makers from low-fertility countries our results are encouraging because intra-household allocations of bargaining power can be affected by policies (BRownING ET AL. [2006]). Moreover, the understanding of decisions about household public goods as bargaining outcomes is crucial to welfare analysis, because housing, children's education and mutual savings are among the largest investments families make. If intra-household allocations of bargaining power are determinants of such decisions, policies that shift bargaining power within couples (e.g. pension regulations rewarding parenting or child care helping mothers to reconcile work and family life and to evade human capital depreciation) can have non-trivial side effects.

The remainder of the paper is organized as follows. We lay out the theoretical background of bargaining over fertility in Section II and describe the empirical strategy and the data in Section III and Section IV. We show estimation results in Section V and conclude in Section VI.

\section{Theoretical Considerations}

We use a simple model of household decision making about the number of children to illustrate the expected effects of bargaining power. In our model, which is based on IYIGUN and WALSH [2007], each household is comprised of one woman $(f)$ and one man $(m)$. Throughout we use the notation $i \in\{f, m\}$ to refer to either of the two. Individual $i$ 's preferences are represented by a strictly increasing and strictly quasi-concave utility function defined over private consumption $\left(c_{i}\right)$, leisure $\left(l_{i}\right)$ and the number of children $(n)$. Since our aim is to provide a model that is tractable and, at the same time, shows how fertility choices are influenced by the relative bargaining power within the household, we consider an additively separable and homothetic utility representation of preferences:

$$
U^{i}\left(c_{i}, l_{i}, n\right)=\ln c_{i}+\ln l_{i}+\alpha_{i} \ln n ; \quad i=f, m .
$$

where $\alpha_{i}>0$ represents the child preferences of person $i$. Each individual can earn a wage in the labor market equal to $w_{i}$, and is endowed with one unit of time which has to be allocated between leisure and market work. In addition, each child requires child-rearing time $\tau$, which is borne by the woman alone. The couple decides the optimal number of children $n$, so that $\tau n$ is total child-rearing time. The woman's time endowment then becomes $(1-\tau n)$; that 
of the male partner is 1 . The assumption can be relaxed to allow the man to spend time on child rearing, but the extreme case of the woman being solely responsible is chosen to illustrate that even though an increase in her wage has a negative opportunity cost effect on fertility, there can be offsetting positive effects which operate over an increase in her bargaining power if $\alpha_{f}>\alpha_{m}$.

Household decisions are made by means of collective bargaining between the partners with $\theta$, with values from zero to one, being the woman's bargaining power, and $(1-\theta)$ the man's bargaining power. We assume that the woman's bargaining depends positively on her relative wage $\phi \equiv w_{f} / w_{m}$. Formally, $\theta=\theta(\phi)$ with $\theta^{\prime}>0$. Couples maximize

$$
\max _{c_{f}, c_{m}, l_{f}, l_{m}, n} \Omega=\theta(\phi) U^{i}\left(c_{f}, l_{f}, n\right)+[1-\theta(\phi)] U^{i}\left(c_{m}, l_{m}, n\right),
$$

subject to

$$
c_{f}+c_{m}+w_{f} l_{f}+w_{m} l_{m}=w_{f}(1-\tau n)+w_{m} .
$$

As we mentioned above, the woman's potential time available for market work is reduced by the time spent child rearing $\tau n$, while the man's time endowment is unity. For an interior solution, the household allocation of resources satisfies the following three criteria:

$$
\begin{gathered}
\frac{U_{2}^{f}\left(c_{f}, l_{f}, n\right)}{U_{1}^{f}\left(c_{f}, l_{f}, n\right)}=w_{f} \\
\frac{U_{2}^{m}\left(c_{m}, l_{m}, n\right)}{U_{1}^{m}\left(c_{m}, l_{m}, n\right)}=w_{m} \\
\frac{U_{3}^{f}\left(c_{f}, l_{f}, n\right)}{U_{1}^{f}\left(c_{f}, l_{f}, n\right)}+\frac{U_{3}^{m}\left(c_{m}, l_{m}, n\right)}{U_{1}^{m}\left(c_{m}, l_{m}, n\right)}=\tau w_{f}
\end{gathered}
$$

where $U_{k}^{i}\left(c_{i}, l_{i}, n\right)$ denotes the first-order partial derivative of $U_{k}^{i}$ with respect to its $k$-th argument $(k=1,2,3)$. For each individual, the marginal rate of substitution between private consumption and leisure must be equal to the marginal rate of transformation, given by the respective market wage [equations (4) and (5)]. The optimal number of children is governed by the Samuelson condition for the optimal provision of a public good [equation (6)]. Stated in words, it implies that the sum of the partners' marginal rates of substitution between having children and private consumption must be equal to the private opportunity cost of an extra child, $\tau w_{f}$, relative to an extra unit of private consumption.

If we employ the additively separable and homothetic utility representation assumed 
above, the optimal number of children is given by:

$$
n^{*}=\frac{(\phi+1)\left[\alpha_{f} \theta(\phi)+\alpha_{m}(1-\theta(\phi))\right]}{\tau \phi\left[2+\alpha_{f} \theta(\phi)+\alpha_{m}(1-\theta(\phi))\right]},
$$

where $\phi=w_{f} / w_{m}>0$. In the empirical work, we examine how fertility choices vary with the wage of women relative to that of their male partners. It is therefore useful to compute:

$$
\frac{\partial n^{*}}{\partial \phi}=\underbrace{-\left[\frac{\alpha_{f} \theta(\phi)+\alpha_{m}(1-\theta(\phi))}{\tau \phi^{2}\left[2+\alpha_{f} \theta(\phi)+\alpha_{m}(1-\theta(\phi))\right]}\right]}_{\text {relative cost effect }}+\underbrace{\left[\frac{2 \theta^{\prime}(\phi)(\phi+1)\left(\alpha_{f}-\alpha_{m}\right)}{\tau \phi\left[2+\alpha_{f} \theta(\phi)+\alpha_{m}(1-\theta(\phi))\right]^{2}}\right]}_{\text {bargaining power effect }}
$$

Consider each element of Equation (8). The first term captures the marginal change in the optimal number of children due to the relative cost effect of rising relative female wages; its sign is negative. Rising female wages relative to male wages make it more expensive for the couple to invest her time into child care and, thus, fertility decreases. The second term captures a "bargaining power effect". Indeed, while rising relative wages tend to increase women's labor supply and, due to higher relative costs, lower fertility, they also lead to a reallocation of bargaining power from men to women. If women have stronger preferences for children than their male partners $\left(\alpha_{f}>\alpha_{m}\right)$, then the reallocation of bargaining power from men to women induced by rising relative wages works to increase fertility. Conversely, when women have weaker preferences for children than their male partners $\left(\alpha_{f}<\alpha_{m}\right)$, the bargaining power effect is negative. Finally, for couples with identical child preferences $\left(\alpha_{f}=\alpha_{m}\right)$, there exists no conflict over the optimal number of children, and hence fertility is unaffected by a reallocation of bargaining power. In the empirical analysis, we will therefore identify bargaining power effects by comparing how the fertility choices of couples with discordant and concordant child preferences vary with the relative female wage within the household.

Overall, the bargaining power effect of rising relative wages could undo the corresponding negative relative cost effect and result in an increase in fertility. This is depicted in Figure 1 , which illustrates the conditions under which an increase in $\phi$ yields positive and negative fertility responses, respectively. With identical child preferences $\left(\alpha_{m}=\alpha_{f}\right)$, the bargaining power effect is zero and so the relative cost effect results in a smaller number of children. In area I, the woman's child preferences are weaker than her male partner's $\left(\alpha_{f}<\alpha_{m}\right)$ and hence, the relative cost effect and the bargaining power effect both work to reduce fertility. In area II, the negative relative cost effect is counteracted by a positive bargaining power effect $\left(\alpha_{f}>\alpha_{m}\right)$. In area IIa, the relative cost effect dominates the bargaining power effect, and so rising female wages reduce fertility. In area IIb, however, the negative relative cost 


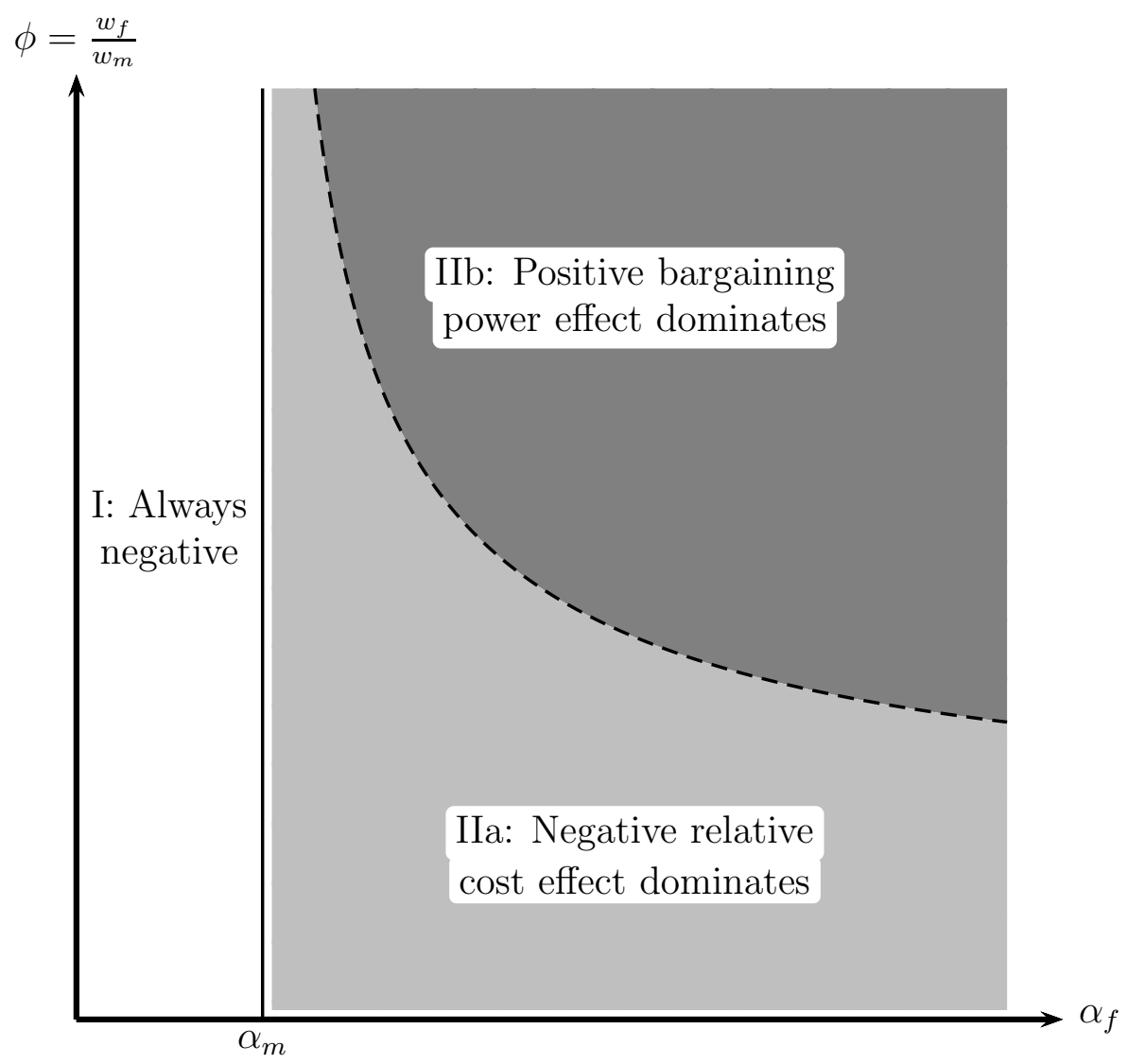

FiguRE 1: Areas of Fertility Response to Increases in the Woman's Relative Wage

Notes: To draw the graph we assume for simplification a linear bargaining power function such that $\theta(\phi)=w_{f} / w_{m}$. The graph shows areas of positive and negative fertility response to the woman's relative wage and relative child preferences. The man's child preferences are fixed at $\alpha_{m}$ and the woman's child preferences $\alpha_{f}$ vary on the horizontal axis. In area I, fertility reacts unambiguously negative, as the relative cost effect and the bargaining power effect work in the same direction. In area II the relative cost effect is negative whereas the bargaining power effect is positive. In area IIa the relative cost effect dominates the bargaining power effect, in area IIb the bargaining power effect dominates the relative cost effect.

effect is more than offset by the positive bargaining power effect, and so couples will choose to have more children as the relative female wage increases. Motivated by these observations, the primary objective of empirical analysis to follow is to disentangle the total effect of rising relative wages into a relative cost and a bargaining power effect.

We conclude the theoretical section with a note on intertemporal efficiency. Intrahousehold allocations can be ex ante Pareto efficient if all members commit to all future changes in allocations of bargaining power such that only the resource allocation at the time of household formation matters. In the absence of full commitment household decisions depend on the bargaining power of household members in the respective period. As a consequence, only in the latter case policy can affect household decisions via alterations of the bargaining power within households. It is crucial whether households can and are 
willing to commit to the ex ante allocation. This argument is made by MAzzocco [2007] , who rejects empirically the assumption of full commitment in households. Our theoretical model is a static simplification of the dynamic process. As full commitment is not a realistic assumption, the empirical tests do not rely on ex ante allocations. Rather, bargaining power and decisions are evaluated in each period by repeating the decision making. This ignores forward looking behavior of individuals in terms of expected alterations of bargaining power after a child birth. Moreover, fertility decisions are irreversible and affect all future decisions. Therefore, we account for the number of children in the empirical analysis such that only couples with the same number of children are compared. In the empirical application fertility decisions are repeated bargaining solutions with contemporaneous allocations conditional on the number of children.

\section{Empirical Strategy}

From the theoretical model we obtain the following main predictions as a basis of our empirical strategy:

1. There is a negative relative cost effect from relative wages of females on births.

2. There is a bargaining power effect from relative wages of females on births, which is

- zero if $\alpha_{f}=\alpha_{m}$,

- positive if $\alpha_{f}>\alpha_{m}$,

- and negative if $\alpha_{f}<\alpha_{m}$.

In essence, it means that female relative wage has a differential effect depending on relative child preferences within a couple additionally to its own relative cost effect on births. The bargaining power effect from female relative wage is positive if $\alpha_{f}>\alpha_{m}$ and negative if $\alpha_{f}<\alpha_{m}$. The net effect of female relative wage is ambiguous. These different effects can be captured by interactions between preference difference $\left(\alpha_{f}-\alpha_{m}\right)$ and relative wages in the following estimation equation:

$$
\begin{aligned}
\text { Birth }_{i, 12-23 m o n t h s}= & \beta_{0}+\beta_{1} \varphi_{i, t}+\beta_{2}\left(\alpha_{f}-\alpha_{m}\right)_{i, t} \\
& +\zeta\left(\varphi \times\left(\alpha_{f}-\alpha_{m}\right)\right)_{i, t} \\
& +X_{i, t}^{\prime} \delta+\epsilon_{i, t},
\end{aligned}
$$

with variables of couple $i$ in period $t$. The dependent variable indicates a birth 12 to 23 months after the interview month. $\varphi$ is our proxy of female bargaining power, reflecting her 
fraction of the couples total wage with values from zero to one. Thus, $\beta_{1}$ is the estimate of the relative cost effect. The bargaining power effects are now captured by interactions of $\varphi$ with the difference in preferences. $\left(\alpha_{f}-\alpha_{m}\right)$ can take on negative and positive values. The interaction $\left(\varphi \times\left(\alpha_{f}-\alpha_{m}\right)\right)_{i, t}$ picks up the differential bargaining power effect, which varies with preference differences. Essentially, the interaction effect captures whether changes in bargaining power affect birth probability differently across couples with concordant and discordant child preferences. Estimates of the interaction effects are our primary target to identify bargaining over fertility as reflected by Equation (8). If $\alpha_{f}>\alpha_{m}$, the difference takes on a positive value, and hence, her bargaining power effect on fertility is positive. Accordingly, if $\alpha_{f}<\alpha_{m}$, the difference takes on a negative value, and hence, her bargaining power effect on fertility is negative. We assume linearity of the preference difference in the bargaining power effect. Thus, we expect that the larger the difference in child preferences is, the larger is the bargaining power effect. This implies for the expected sign that $\zeta>0$.

To control primarily for different compositions of the groups denoted by $I($.$) , we include$ a vector of control variables $X$. These include the age and age squared of both partners, household income, as well as indicator variables for being a student, for foreign citizenship and second-generation immigrants, for federal states, and for the number of children, and year fixed effects. In different specifications we also control for the sum of both partners' child preferences and for the female wage rate. $\epsilon$ is an i.i.d. error term.

In a second attempt, we drop the linearity assumption of the preference differences and disentangle the effects for couples with concordant and discordant child preferences. To do that we use separate indicator variables for couples in which the female partner has higher child preferences and in which she has lower child preferences in the estimation equation

$$
\begin{aligned}
\text { Birth }_{i, 12-23 m o n t h s}= & \beta_{0}+\beta_{1} \varphi_{i, t}+\beta_{2} I\left(\alpha_{f}>\alpha_{m}\right)_{i, t}+\beta_{3} I\left(\alpha_{f}<\alpha_{m}\right)_{i, t} \\
& +\gamma_{1}\left(\varphi \times I\left(\alpha_{f}>\alpha_{m}\right)\right)_{i, t} \\
& +\gamma_{2}\left(\varphi \times I\left(\alpha_{f}<\alpha_{m}\right)\right)_{i, t} \\
& +X_{i, t}^{\prime} \delta+\epsilon_{i, t} .
\end{aligned}
$$

$I($.$) is an indicator function taking the value of one if true and zero if false. It divides the$ sample in three groups. $I\left(\alpha_{f}>\alpha_{m}\right)$ takes on a value of one if the female's child preferences are stronger than the male partner's. $I\left(\alpha_{f}<\alpha_{m}\right)$ takes on a value of one if the female's child preferences are weaker than the male partner's. Both are zero if the couple has concordant child preferences, reflecting the comparison group. The interactions $\left(\varphi \times I\left(\alpha_{f}>\alpha_{m}\right)\right)_{i, t}$ and $\left(\varphi \times I\left(\alpha_{f}<\alpha_{m}\right)\right)_{i, t}$ capture the differential bargaining power effects. Hence, $\gamma_{1}$ and $\gamma_{2}$ are estimates of bargaining power effects. Essentially, we estimate whether relative female wage 
has different effects between the groups denoted by $I($.$) . According to theory, we expect the$ estimates to have the properties $\gamma_{1}>0$ and $\gamma_{2}<0$.

Estimation bias. Estimations of the bargaining power effect in $\zeta, \gamma_{1}$, and $\gamma_{2}$ may suffer from endogeneity due to omitted variable bias. It arises if unobserved factors are correlated with both the dependent variable births and the interaction of relative wages with the preference indicators. A plausible scenario is that women with high preferences for having children invest less in market human capital. Consequently, there would be many couples with strong female preferences and low female bargaining power who have a high probability of getting a child. On the other hand, women with a low desire for children would invest more in market human capital. Couples would have low female child preferences and high female bargaining power if they are unlikely to have a child. Thus, it is unclear whether this kind of selection induces an upward or downward bias on our estimate of the bargaining power effect. We run two robustness regressions to reduce the probability of confounding variation driving our results by restricting the sample (i) to couples with no child and (ii) to couples with a full-time employed female. Moreover, we control for the level of child preferences, the actual number of children and household income of the couples. Thus, the estimation compares couples with the same combined desire for children and the same number of realized children. By using interaction effects we estimate the effect of bargaining power on births for couples with equal child preferences and compare it to the effect for couples with discordant child preferences. The difference in the effects gives us the measure of a bargaining power effect on fertility reflected by the interaction term. Estimating this bargaining power effect is therefore rather robust, but not too much weight should be put on estimates of the relative cost effect which is purely identified in the cross-section.

\section{Data}

We use data from the German Socio-Economic Panel (SOEP) in Version 27 for our estimations. ${ }^{5}$ We apply waves from 1990 onwards. Data include information on the socioeconomic background of individuals and households, and on intra-family relations. Partners, cohabiting or married, are matched by partner identifiers to obtain a comprehensive couple data set. We include only couples in which the woman is of reproductive age (between 18 and 49 years old). The anchoring person in our data set is the woman. Her characteristics along with matched partner characteristics are used in the empirical analysis. Given the setup, we have two variables of interest: child preferences and proxies for bargaining power.

\footnotetext{
${ }^{5}$ See WAGNER ET AL. [2007] for further information on the data.
} 
Child preferences. For child preferences we use proxy data from a question, which asks about the importance of having children. The precise question is: "Are the following things ("Have children") currently ... very important (4), important (3), not very important (2) or totally unimportant (1) ... for you?" 6 The question is only included in waves 1990, 1992, 1995, 2004, and 2008; this restricts our sample period.

As our preference variable is in fact a proxy of child preferences, we make some attempts to verify its validity. Our child preferences are not fertility preferences in the sense of a desired number of children, but self-reported valuation of how important having children is. This variable may reflect a variety of underlying preferences and valuations of current situations. In part, the variable can be understood as the parents' evaluations of being a family with children, how satisfied they are with their family or how much they care about their offsprings. The number of current children will thus be correlated with stated child preferences. For our purpose, we need at least in some sense a connection of the preference variable to the real preference for having another child. We show in Figure 2 how the stated preferences of childless couples translate into completed fertility in later waves. The assumption is that childless couples cannot evaluate their current situation with their offsprings when answering the survey question and therefore state a preference for a family with children. Completed fertility can be measured by following the same couples over time in the panel. In Figure 2 we depict the average number of children at the latest observation on the ordinate, reflecting average completed fertility, and the answer to the preference question on the abscissa. We see a clear positive correlation of stated preferences when childless and average completed fertility, both for males and females. In general, our stated child preferences have predictive power for completed fertility. Hence, our child preference variable seems to be a good proxy for actual child preferences.

Another general concern is that preferences in conventional terms are stable over time and should not be malleable. For the majority of individuals in our data the child preference variable is time-constant. In our sample, 78 percent of the women do not change their stated child preference ${ }^{7}$ (73 percent of the male partners). Another 16 percent change it by a total of a one-point shift over the four categories (20 of the male partners). Measurement error is very likely to occur with this kind of subjective measure and may well explain large parts of the within-individual variation that is reflected in increasing volatility with number of

\footnotetext{
${ }^{6}$ This coding is in reversed order compared to the original data. Hence, for our analysis larger numbers correspond to stronger preferences.

${ }^{7} 44$ percent are only observed once in years with observation of the child preference question. The percentage decreases with interview-years in the panel per individual. For women with two interviews 67 percent do not change their preference answer.
} 

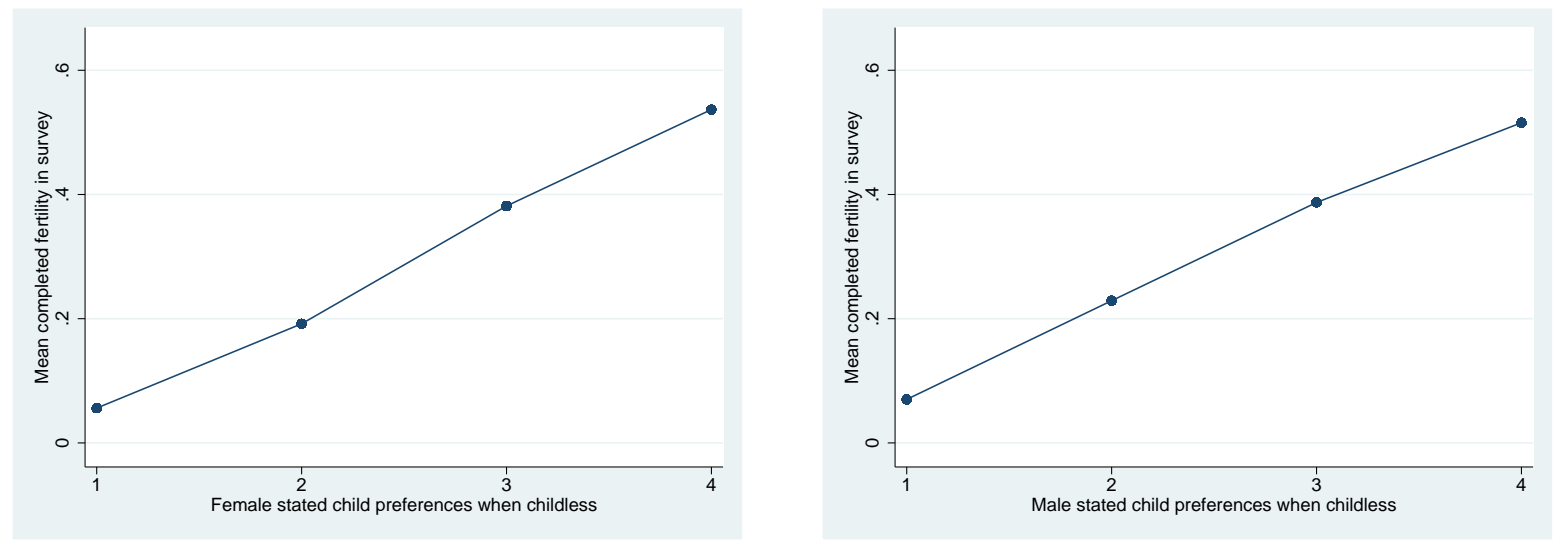

Figure 2: Completed Fertility and Initial Child Preferences

Notes: The figure in the left panel depicts a scatter plot with the average, latest observed number of children on the ordinate for each female child preference answer while childless. The figure in the right panel depicts a scatter plot with the average, latest observed number of children on the ordinate for each male child preference answer while childless.

interviews in the panel. Although measurement error may be severe, our variable partly reflects time-stable child preferences.

In Table I we cross-tabulate the number of answers to the child preference question from women in rows and from their male partners in columns. The two highest categories contain by far the most answers, although males are less likely to answer in the highest category than females. We define all observations on the diagonal as couples with concordant child preferences. Couples with stronger child preferences of females are found to the northeast of the diagonal, such that $I\left(\alpha_{f}>\alpha_{m}\right)$ takes on the value of one and is zero otherwise. Accordingly, observations to the southwest of the diagonal denote couples with weaker female child preferences, such that $I\left(\alpha_{f}<\alpha_{m}\right)$ takes on the value of one and is zero otherwise. Thus, we have 8,775 observations of couples with concordant child preferences, 3,099 observations of couples with higher female child preferences and 1,513 observations of couples with lower female child preferences.

Table I: Child PREFERENCE COMBINATIONS

\begin{tabular}{|c|c|c|c|c|c|c|}
\hline Woman: & Male partner: & $\begin{array}{r}\text { Very } \\
\text { important }\end{array}$ & Important & $\begin{array}{r}\text { Not very } \\
\text { important }\end{array}$ & $\begin{array}{r}\text { Totally } \\
\text { unimportant }\end{array}$ & Total \\
\hline Very important & & 6,037 & 2,207 & 278 & 47 & 8,569 \\
\hline Important & & 962 & 2,027 & 402 & 52 & 3,443 \\
\hline Not very important & & 70 & 319 & 510 & 113 & 1,012 \\
\hline Totally unimportant & & 11 & 48 & 103 & 201 & 363 \\
\hline Total & & 7,080 & 4,601 & 1,293 & 413 & 13,387 \\
\hline
\end{tabular}


We report some general descriptive statistics of the data in Table II. The sample is restricted to non-missing values for the dependent and all control variables which are used later on. 23 percent of couples show stronger female child preferences and thus are subsumed under the indicator variable $I\left(\alpha_{f}>\alpha_{m}\right)$. 11 percent of couples belong to the other group with discordant child preferences, in which $I\left(\alpha_{f}<\alpha_{m}\right)$ equals one. Accordingly, 66 percent of couples have concordant child preferences.

Table II: DescRIPTIVE STATISTICS

\begin{tabular}{|c|c|c|c|c|c|}
\hline Variable & $\mathrm{N}$ & Mean & Std. Dev. & Min & Max \\
\hline \multicolumn{6}{|l|}{ Dependent variable } \\
\hline Birth $_{12-23 m o n t h s}$ & 11,386 & 4.15 & 19.95 & 0 & 100 \\
\hline \multicolumn{6}{|l|}{ Variables of interest } \\
\hline$I\left(\alpha_{f}>\alpha_{m}\right)$ & 11,386 & 0.23 & 0.42 & 0 & 1 \\
\hline$I\left(\alpha_{f}<\alpha_{m}\right)$ & 11,386 & 0.11 & 0.31 & 0 & 1 \\
\hline$\left(\alpha_{f}-\alpha_{m}\right)$ & 11,386 & 0.15 & 0.68 & -3 & 3 \\
\hline$\varphi:$ Relative wage & 10,806 & 0.46 & 0.13 & 0.03 & 0.97 \\
\hline$\varphi:$ Relative labor income & 11,386 & 0.29 & 0.26 & 0 & 1 \\
\hline \multicolumn{6}{|l|}{ Control variables } \\
\hline Sum of child preferences & 11,386 & 6.89 & 1.36 & 2 & 8 \\
\hline Household income (monthly) & 11,386 & 3,203 & 1,606 & 119 & 56,760 \\
\hline Age & 11,386 & 36.75 & 7.53 & 18 & 49 \\
\hline Partner's age & 11,386 & 39.70 & 8.47 & 19 & 82 \\
\hline In education & 11,386 & 0.06 & 0.24 & 0 & 1 \\
\hline Non-German & 11,386 & 0.10 & 0.29 & 0 & 1 \\
\hline Second gen. migrant & 11,386 & 0.02 & 0.15 & 0 & 1 \\
\hline Number of children & 11,386 & 1.57 & 1.11 & 0 & 11 \\
\hline
\end{tabular}

Notes: Descriptive statistics of the sample including: number of observations (N), mean, standard deviation (Std. Dev.), minimum (Min) and maximum (Max). All variables are defined from the perspective of women with male partners. The sample is restricted to all observations with non-missing observations of all control variables and the relative labour income variable.

In another specification we exploit the extent of the difference in child preferences between 
partners. We define the difference in preferences as $\alpha_{f}-\alpha_{m}$. The variable can take on values between -3 and +3 , with negative values indicating lower female child preferences and positive values indicating higher female child preferences. The variable is zero for couples with concordant child preferences. We see in Table II that on average the variable is 0.15 , which corresponds to slightly stronger female child preferences.

Proxies for bargaining power. A plethora of measures can act as determinants of bargaining power in couples. Here, we focus on financial factors. In standard consumption theory own earnings affect own consumption. Equivalently we assume that own earnings affect the share of consumption or say in the household in the bargaining framework. From an empirical perspective, using earnings or realized wages causes problems. The observed wage is likely to be endogenous in the bargaining decisions of couples. This means that the outside option used as a threat point is not necessarily the same as the equilibrium outcome as POLLAK [2005] points out. Intuitively, a female partner could stay out of the labor market to spend more time in home production and therefore earn zero market wages. However, this would not reveal her potential wage in the event of a divorce used as a threat point. Thus, we follow Pollak [2005], Aizer [2010] and Datta Gupta and Stratton [2010] in arguing that potential rather than observed wage is our preferred determinant of bargaining power.

The selection into non-market work is particularly prevalent for females. We observe one in four of the female spouses in our sample with a wage of zero, which is most likely due to voluntary absence from market-work. This assumption is supported by DoLTON and MAKEPEACE [1986], who report that 29 percent of the women in their sample stopped working for domestic reasons. Because the potential wage is not observable in the data, we need to correct for zero female wages. Women staying at home are not randomly selected, which we account for by using a HECKMAN [1979] sample selection model. The basic procedure is to estimate a selection equation for participating in the labor market in the first stage and to estimate a wage equation in the second stage. Then, the estimates are used to predict the potential wage for non-participating women. ${ }^{8}$ We use a simple version of a wage equation defined by

$$
\ln (w)=V^{\prime} \eta_{1}+u_{1}
$$

where $\ln (\mathrm{w})$ is the natural logarithm of the hourly wage $\mathrm{w}$, defined as the preceding years total cpi corrected labor earnings over the number of hours worked. Using measures from the previous year minimizes the possibility that wages are adjusted in the awaiting of a child.

\footnotetext{
${ }^{8}$ We use the full sample for the predictions which increases the number of observations considerably compared to the sample with information on child preferences.
} 
$\mathrm{V}$ is a vector including dummies for each category of the ISCED codes for education as well as own age and the survey wave. Wages are only observed if the woman works. Thus, if selection is non-random, estimates would be inconsistent. The decision to work is described by

$$
Y=Z^{\prime} \eta_{2}+u_{2}
$$

where $\mathrm{Y}$ is unity for non-zero working hours and zero otherwise. $\mathrm{Z}$ is a vector of the variables in $\mathrm{V}$ and the number of children as an additional regressor for the identification of the selection. The coefficients are obtained in a Probit regression. The Heckman twostep approach yields the inverse Mill's ratio from the selection equation which is used to consistently estimate the wage equation accounting for selection into market-work. We use the prediction of the two-stage estimation to obtain the potential wage rate of females. For males, the selection into market-work is less important. Most of the zero wages are probably due to unemployment. We exclude males without earnings from the relative wage measure. We follow Datta Gupta and Stratton [2010] by defining the relative wage as $w_{f} /\left(w_{f}+w_{m}\right)$ with $w_{f}$ being the potential female wage and $w_{m}$ being the observed male wage. According to Table II the female share in wage rates is on average 46 percent.

The relative wage rate is the prime measure for bargaining power, but we also consider alternatives like actual earnings. First, it may be important how much money each spouse brings in, in particular if we think of the bargaining process as continuously repeated decision making. When partners evaluate their bargaining position over and over again, the information on actual earnings is much more easily accessed than potential earnings. Second, we want to demonstrate the sensitivity of the results with respect to the predicted female wage rates. Therefore, we apply relative labor earnings as another proxy of bargaining power. It is defined as $y_{f} /\left(y_{f}+y_{m}\right)$ with $y_{f}$ being the observed female labor earnings and $y_{m}$ being the observed male labor earnings. We again use values of the previous year to minimize adjustments to a coming child. The female share in labor earnings is on average 29 percent and thus considerably lower than the wage share. We need to keep in mind that actual earnings represent the equilibrium outcome of a couple's division of labor including women with zero earnings due to specialization in home production.

Births. Our dependent variable throughout the empirical analysis is births. A birth is defined as having a child 12 to 23 months after the interview. We employ a conception and gestation lag of at least 12 months because we are interested in the decision about having a child and the conditions at the time the decision was probably made. Clearly, our fertility variable is a rather noisy measure of the intention to have a child. The variable is an indicator variable taking on a value of one if the woman gives birth 12 to 23 months 
after the interview and zero otherwise. We observe 506 births, of which 327 are from couples with concordant child preferences, and 179 from couples with discordant child preferences. The majority of 131 fall into the group with higher female child preferences, 48 into the group with lower female child preferences. The dependent variable as depicted in Table II is an indicator for a birth 12 to 23 months after the interview. The measure is multiplied by 100 as it is used in the estimations to get more convenient coefficients. Hence, there are on average 0.0416 births per year and woman.

Control variables. In our sample, as depicted by the control variables in Table II, the sum of couples' child preferences (sum of the categorical child preference variable with values from 1 to 4 ) is on average 6.89 , corresponding to the mostly strong child preferences seen earlier. Household net income averages at about 3200 Euro monthly. Women are on average 36.75 years old, which comes about technically by restricting to the reproductive age from 18 to 49 years. Their male partners are on average 3 years older. About 6 percent participate in some kind of education or training. 10 percent have or had a non-German citizenship. 2 percent are second generation immigrants. The average number of children is 1.57.

\section{Empirical Results}

In this chapter we show baseline results for regressions of birth probability on bargaining power measures and its interactions with preference differences. The bargaining power measures include shares in wage rates and labor earnings. In the robustness analysis, we then disentangle the bargaining power effects by estimating deviations for couples with higher and lower female child preferences. Moreover, we test whether the results hold for childless couples and full-time employed women.

Baseline estimates. We report baseline estimates from linear probability regressions in Table III using the model as in equation (9). In columns (1) to (3), the proxy $\varphi$ for bargaining power is defined as relative female wage. In the first row, the estimates of the interaction effect of relative wage $\varphi$ with the difference in child preferences $\left(\alpha_{f}-\alpha_{m}\right)$, denoting the bargaining effect, show a positive sign. This result is consistent with our theory. The stronger the child preferences of the female partner are relative to her male partner, the more positive is the influence of her relative potential wage on the probability of birth. The estimate is insignificant without controls in the first column, but becomes statistically significant at the 5 percent level when including standard control variables and total real household income in the second column. Even when controlling for the sum of child preferences in the third column, the estimate of the bargaining power effect is statistically significant and comparable in size. According to the most complete specification, for each point of difference 
between the female and her partner's child preference, ranging from -3 to +3 , an increase in her relative wage by 10 percentage points increases birth probability by 0.4 percentage points compared to couples with equal child preferences. This effect can be considered to be significant in size as the average birth probability is about 4 percent.

Estimates of the bargaining power effect using the alternative specification with relative labor earnings in columns (4) to (6) of Table III are positive as well and statistically significant at least at the 5 percent level. Compared to the estimates based on wage rates with control variables the effect sizes are somewhat smaller. Interpreting the coefficients gives us an estimate of how much more fertility reacts to an increase in bargaining power for couples who have a one point higher relative female child preference than other couples. Increasing the share in female labor income by ten percentage points increases birth probability by 0.24 percentage points for these couples. Thus, the overall conclusion does not depend on the particular form of the bargaining power proxy. Both forms, the relative potential wage and the observed, actual earnings yield results compatible with a bargaining power effect on fertility.

The correlation of births with $\varphi$ are negative in five of the specifications, but only statistically significant in column (4). The indirect effect of higher female weights in the household decisions do not seem to have a strong impact on the probability to have a child. The correlation with the difference in child preferences are negative in five specifications and never statistically significant. Actual household income is positively associated with births, but only statistically significant in columns (2) and (5). A positive effect is consistent with normality of children. In the full specification income loses significance. Consistent with expectations the sum of child preferences of both partners affects birth probability positively and statistically significantly at the one percent level. If one of the partners answers one category higher in the child preference question, the probability of child birth is increased by 1.7 percentage points. The point estimate is very stable across different specifications.

\section{V.1. Robustness and sensitivity tests}

A very intuitive version of the main theoretical result is that female bargaining power positively affects birth probability if she has stronger child preferences than her partner. On the other hand, if she has weaker child preferences than her partner, her bargaining power affects birth probability negatively. We directly use this formulation when estimation equation (10). Instead of using a linear difference of child preferences, we form three groups of couples with either stronger female, equal or weaker female child preferences. Couples with equal child preferences are the omitted group. This exercise disentangles the earlier results. In Table IV we see the two bargaining power effects in the first two rows. As 
Table III: BASELINE-BARGAINING POWER EFFECTS FOR WAGE AND INCOME WITH PREFERENCE DIFFERENCES

\begin{tabular}{|c|c|c|c|c|c|c|}
\hline \multirow[t]{2}{*}{ Bargaining power proxy $\varphi$ : } & \multicolumn{3}{|c|}{ Relative wage } & \multicolumn{3}{|c|}{ Relative income } \\
\hline & $(1)$ & $(2)$ & $(3)$ & (4) & $(5)$ & $(6)$ \\
\hline$\varphi \times\left(\alpha_{f}-\alpha_{m}\right)$ & $\begin{array}{c}2.3784 \\
(1.8956)\end{array}$ & $\begin{array}{c}3.7602^{* *} \\
(1.8876)\end{array}$ & $\begin{array}{c}4.0866^{* *} \\
(1.8921)\end{array}$ & $\begin{array}{c}2.8402^{* * *} * \\
(1.0501)\end{array}$ & $\begin{array}{c}2.6912^{* * *} \\
(1.0298)\end{array}$ & $\begin{array}{c}2.4215^{* *} \\
(1.0297)\end{array}$ \\
\hline$\varphi$ & $\begin{array}{c}-0.8266 \\
(1.5132)\end{array}$ & $\begin{array}{c}-0.2047 \\
(1.9327)\end{array}$ & $\begin{array}{c}0.2118 \\
(1.9300)\end{array}$ & $\begin{array}{c}-2.7876^{* * *} \\
(0.7424)\end{array}$ & $\begin{array}{l}-0.6951 \\
(0.7886)\end{array}$ & $\begin{array}{l}-0.2443 \\
(0.7918)\end{array}$ \\
\hline$\left(\alpha_{f}-\alpha_{m}\right)$ & $\begin{array}{c}-0.6310 \\
(0.9520)\end{array}$ & $\begin{array}{c}-1.3568 \\
(0.9472)\end{array}$ & $\begin{array}{l}-1.2243 \\
(0.9505)\end{array}$ & $\begin{array}{c}-0.2996 \\
(0.4525)\end{array}$ & $\begin{array}{l}-0.3318 \\
(0.4360)\end{array}$ & $\begin{array}{c}0.0323 \\
(0.4395)\end{array}$ \\
\hline Household income & & $\begin{array}{c}0.0002^{* *} \\
(0.0001)\end{array}$ & $\begin{array}{c}0.0001 \\
(0.0001)\end{array}$ & & $\begin{array}{c}0.0002^{* *} \\
(0.0001)\end{array}$ & $\begin{array}{c}0.0002 \\
(0.0001)\end{array}$ \\
\hline Sum of preferences & & & $\begin{array}{c}1.6980^{* * *} \\
(0.1871)\end{array}$ & & & $\begin{array}{c}1.6876^{* * *} \\
(0.1805)\end{array}$ \\
\hline Number of children fixed effects & Yes & Yes & Yes & Yes & Yes & Yes \\
\hline Control variables & & Yes & Yes & & Yes & Yes \\
\hline Observations & 11,155 & 10,806 & 10,806 & 11,744 & 11,386 & 11,386 \\
\hline
\end{tabular}

Notes: Coefficients from linear probability estimations with the dependent variable birth 12 to 23 months after the interview and multiplied by 100. The estimate of $\varphi \times\left(\alpha_{f}-\alpha_{m}\right)$ denotes the bargaining power effect. $\varphi$ is defined as the female's measure over the sum of both partners' measures. Robust standard errors from clustering on couples in parentheses, ${ }^{* * *}$ $\mathrm{p}<0.01,{ }^{* *} \mathrm{p}<0.05,{ }^{*} \mathrm{p}<0.1$. Number of child fixed effects include an indicator variable for each contemporaneous number of children. Additional control variables include age and age squared of both partners, an indicator variable for being a student, indicator variables for foreign citizenship and second-generation immigrants, indicator variables for federal states, and year fixed effects. Data source: SOEP. 
predicted in the theory, both show the expected signs - positive for stronger female child preferences and negative for weaker female child preferences - across all specifications. With relative wage as the bargaining power proxy, only two of the negative interaction effects are statistically significant at least at the ten percent level. The effect sizes are larger than in the baseline estimation, which is expected as the indicator for weaker preferences comprises of differences between -3 and -1 . With labor income as the bargaining power proxy, the positive interaction effects are all statistically significant and also larger than the baseline estimates. The negative interaction effects are only significant at the ten percent level in the full specification. Although the precision of the bargaining power estimates alternates, the pattern of the estimates' signs is fully compatible with our theory. The baseline result seems not to be driven by either women who want children less or more than their partner, but instead it is a general phenomenon.

A major concern with the robustness of the estimation is that child preferences and wages or incomes are endogenous. These measures could change after a childbirth and there could be self-selection, e.g. into low market human capital and more children. This could cause serious endogeneity problems in the estimation yielding inconsistent estimates. Therefore, we run estimations on two subsamples that are less prone to this bias - a sample of childless couples and a sample of full-time employed women. ${ }^{9}$

We begin with a sample on childless couples in Table V. The number of observations drops to a maximum 2,251 couples. They account for less than half of all births. The estimated bargaining power effects for relative wages have the expected positive sign, but they are not statistically significant. Standard errors are large, which could be due to the small sample and measurement error in the potential wage. The estimates are also somewhat larger than in the full sample. ${ }^{10}$ With relative income as the bargaining power proxy the estimates are also positive. Standard errors are not as large as in the case of relative wage, such that two of the estimates are just statistically significant at the ten percent level. Overall, the estimates are compatible with previous results. Furthermore, as our preference variables do not necessarily reflect the desire for more children, the findings on childless couples support that the preference variable is appropriate. ${ }^{11}$

The second subsample we consider is comprised of couples with a full-time working female, defined as more than 30 hours a week over a full year. This excludes the self-selection

\footnotetext{
${ }^{9}$ I thank an anonymous referee for suggesting tests on these subsamples.

${ }^{10} \mathrm{~A}$ very similar result is found for a sample with couples that have one child. In a sample with couples that have no or one child, i.e., couples who attempt to have their first or second child, results are similar and become just statistically significant. Result are omitted to keep the number of tables small.

${ }^{11}$ I thank an anonymous referee for suggesting this robustness test.
} 
Table IV: BASELINE-BARGAining POWER EFFECTS FOR WAGE AND INCOME WiTH PREFERENCE INDICATORS

\begin{tabular}{|c|c|c|c|c|c|c|}
\hline \multirow[t]{2}{*}{ Bargaining power proxy $\varphi$ : } & \multicolumn{3}{|c|}{ Relative wage } & \multicolumn{3}{|c|}{ Relative income } \\
\hline & (1) & $(2)$ & $(3)$ & $(4)$ & $(5)$ & (6) \\
\hline$\varphi \times I\left(\alpha_{f}>\alpha_{m}\right)$ & $\begin{array}{c}4.6268 \\
(3.6575)\end{array}$ & $\begin{array}{c}4.0387 \\
(3.6422)\end{array}$ & $\begin{array}{c}4.5579 \\
(3.6423)\end{array}$ & $\begin{array}{c}5.0421^{* * *} \\
(1.8711)\end{array}$ & $\begin{array}{c}4.4684^{* *} \\
(1.8475)\end{array}$ & $\begin{array}{c}3.9242^{* *} \\
(1.8364)\end{array}$ \\
\hline$\varphi \times I\left(\alpha_{f}<\alpha_{m}\right)$ & $\begin{array}{l}-3.8502 \\
(4.3478)\end{array}$ & $\begin{array}{c}-8.4458^{* *} \\
(4.2266)\end{array}$ & $\begin{array}{c}-7.7323^{*} \\
(4.2398)\end{array}$ & $\begin{array}{l}-2.5953 \\
(1.8577)\end{array}$ & $\begin{array}{l}-2.6750 \\
(1.8633)\end{array}$ & $\begin{array}{c}-3.0836^{*} \\
(1.8684)\end{array}$ \\
\hline$\varphi$ & $\begin{array}{l}-1.1030 \\
(1.8001)\end{array}$ & $\begin{array}{c}0.4694 \\
(2.1848)\end{array}$ & $\begin{array}{c}0.7055 \\
(2.1848)\end{array}$ & $\begin{array}{c}-3.2042^{* * *} \\
(0.9579)\end{array}$ & $\begin{array}{l}-0.9909 \\
(1.0092)\end{array}$ & $\begin{array}{l}-0.4564 \\
(1.0121)\end{array}$ \\
\hline$I\left(\alpha_{f}>\alpha_{m}\right)$ & $\begin{array}{l}-2.2545 \\
(1.7530)\end{array}$ & $\begin{array}{l}-1.9692 \\
(1.7525)\end{array}$ & $\begin{array}{l}-1.1678 \\
(1.7477)\end{array}$ & $\begin{array}{c}-1.4820^{* *} \\
(0.6582)\end{array}$ & $\begin{array}{c}-1.3001^{* *} \\
(0.6568)\end{array}$ & $\begin{array}{l}-0.1099 \\
(0.6585)\end{array}$ \\
\hline$I\left(\alpha_{f}<\alpha_{m}\right)$ & $\begin{array}{c}0.1125 \\
(2.1335)\end{array}$ & $\begin{array}{c}2.3786 \\
(2.1059)\end{array}$ & $\begin{array}{c}3.0850 \\
(2.1109)\end{array}$ & $\begin{array}{l}-0.9797 \\
(0.8622)\end{array}$ & $\begin{array}{l}-0.7983 \\
(0.8472)\end{array}$ & $\begin{array}{c}0.3455 \\
(0.8545)\end{array}$ \\
\hline Household income & & $\begin{array}{l}0.0002^{*} \\
(0.0001)\end{array}$ & $\begin{array}{c}0.0001 \\
(0.0001)\end{array}$ & & $\begin{array}{c}0.0002^{* *} \\
(0.0001)\end{array}$ & $\begin{array}{c}0.0001 \\
(0.0001)\end{array}$ \\
\hline Sum of preferences & & & $\begin{array}{c}1.7089^{* * *} \\
(0.1923)\end{array}$ & & & $\begin{array}{c}1.6969 * * * \\
(0.1850)\end{array}$ \\
\hline Number of children fixed effects & Yes & Yes & Yes & Yes & Yes & Yes \\
\hline Control variables & & Yes & Yes & & Yes & Yes \\
\hline Observations & 11,155 & 10,806 & 10,806 & 11,744 & 11,386 & 11,386 \\
\hline
\end{tabular}
and multiplied by 100. The estimate of $\varphi \times I\left(\alpha_{f}>\alpha_{m}\right)$ denotes the positive bargaining power effect and the estimate of $\varphi \times I\left(\alpha_{f}<\alpha_{m}\right)$ the negative bargaining power effect. $\varphi$ is defined as the female's measure over the sum of both partners' measures. Robust standard errors from clustering on couples in parentheses, ${ }^{* * *} \mathrm{p}<0.01,{ }^{* *} \mathrm{p}<0.05,{ }^{*} \mathrm{p}<0.1$. Number of child fixed effects include an indicator variable for each contemporaneous number of children. Additional control variables include age and age squared of both partners, an indicator variable for being a student, indicator variables for foreign citizenship and second-generation immigrants, indicator variables for federal states, and year fixed effects. Data source: SOEP. 
Table V: First BIRThs ONLY — BARgAining POWER EFFECTS With PREFERENCE DiffERENCES

\begin{tabular}{|c|c|c|c|c|c|c|}
\hline \multirow[t]{2}{*}{ Bargaining power proxy $\varphi$ : } & \multicolumn{3}{|c|}{ Relative wage } & \multicolumn{3}{|c|}{ Relative income } \\
\hline & (1) & $(2)$ & $(3)$ & $(4)$ & $(5)$ & (6) \\
\hline$\varphi \times\left(\alpha_{f}-\alpha_{m}\right)$ & $\begin{array}{c}4.1360 \\
(4.6877)\end{array}$ & $\begin{array}{c}6.4609 \\
(4.7882)\end{array}$ & $\begin{array}{c}5.0090 \\
(4.8019)\end{array}$ & $\begin{array}{l}5.1425^{*} \\
(2.7134)\end{array}$ & $\begin{array}{l}5.0709^{*} \\
(2.7152)\end{array}$ & $\begin{array}{c}4.4286 \\
(2.7008)\end{array}$ \\
\hline$\varphi$ & $\begin{array}{c}0.3702 \\
(4.3809)\end{array}$ & $\begin{array}{l}-0.7624 \\
(5.1285)\end{array}$ & $\begin{array}{l}-0.1857 \\
(5.0934)\end{array}$ & $\begin{array}{c}0.1487 \\
(2.1482)\end{array}$ & $\begin{array}{c}-0.2447 \\
(2.2390)\end{array}$ & $\begin{array}{c}0.6274 \\
(2.2330)\end{array}$ \\
\hline$\left(\alpha_{f}-\alpha_{m}\right)$ & $\begin{array}{c}0.1322 \\
(2.2283)\end{array}$ & $\begin{array}{l}-1.7086 \\
(2.2930)\end{array}$ & $\begin{array}{l}-1.0872 \\
(2.2988)\end{array}$ & $\begin{array}{c}0.2336 \\
(1.2957)\end{array}$ & $\begin{array}{c}-0.3832 \\
(1.3010)\end{array}$ & $\begin{array}{l}-0.1628 \\
(1.2928)\end{array}$ \\
\hline Household income & & $\begin{array}{c}0.0003 \\
(0.0003)\end{array}$ & $\begin{array}{c}0.0003 \\
(0.0003)\end{array}$ & & $\begin{array}{c}0.0005 \\
(0.0003)\end{array}$ & $\begin{array}{c}0.0004 \\
(0.0003)\end{array}$ \\
\hline Sum of preferences & & & $\begin{array}{c}2.8572^{* * * *} \\
(0.3819)\end{array}$ & & & $\begin{array}{c}2.8789 * * * \\
(0.3621)\end{array}$ \\
\hline Number of children fixed effects & Yes & Yes & Yes & Yes & Yes & Yes \\
\hline Control variables & & Yes & Yes & & Yes & Yes \\
\hline Observations & 2,077 & 2,007 & 2,007 & 2,251 & 2,180 & 2,180 \\
\hline
\end{tabular}
interview and multiplied by 100. The estimate of $\varphi \times\left(\alpha_{f}-\alpha_{m}\right)$ denotes the bargaining power effect. $\varphi$ is defined as the female's measure over the sum of both partners' measures. Robust standard errors from clustering on couples in parentheses, ${ }^{* *} \mathrm{p}<0.01,{ }^{*} \mathrm{p}<0.05,{ }^{*} \mathrm{p}<0.1$. Number of child fixed effects include an indicator variable for each contemporaneous number of children. Additional control variables include age and age squared of both partners, an indicator variable for being a student, indicator variables for foreign citizenship and second-generation immigrants, indicator variables for federal states, and year fixed effects. Data source: SOEP. 
into non-employment of lower ability women. Results in Table VI reveal a positive bargaining power effect when using relative wages. However, the estimates are not statistically significant and smaller than in the full sample. The potential wages do a poor job in describing the bargaining position. As self-selection into non-employment or part-time jobs is excluded by the sample restriction, we do not need to account for it by predicting the potential wage rate. Using the Heckman selection equation for predictions rather increases measurement error. Thus, actual labor income is the appropriate measure of bargaining power in this sample. The estimated bargaining power effects for relative labor income in columns (4) to (6) are positive and statistically significant in all specifications. Effect sizes are even somewhat larger than in the full sample. This result is consistent with the baseline estimates and suggests that the effect is not solely driven by women with weak labor market attachment.

\section{V.2. Other potential bargaining power measures and fixed effects estimations}

A well-established measure of bargaining power within couples is non-earned income. It has the advantage that it is less affected by individual decisions. The downside is that there is much less variation to exploit. Moreover, we have to restrict this measure to observations with at least one partner having positive non-earned income to make shares a meaningful variable. As only 10 percent of the sample have non-earned income and in most cases only one partner does, results would probably not be meaningful and we do not report estimates with this variable.

As another robustness test and in order to account for unobserved time-invariant heterogeneity, we apply a fixed-effects model which adds a couple fixed effect to the estimation equation. In this approach, estimates are only identified by within-couple variation over time, i.e., only changes in bargaining power and child preferences over time contribute to the identification. This also means that only couples with at least one observation without and one observation with a birth are used in the identification. With five observations over time at maximum the variation left is arguably little. Fixed effects estimates of the bargaining power effect using relative wage are positive, but statistically insignificant and very small. Using relative labor income yield positive and statistically insignificant estimates as well. The size is also smaller than from cross-sectional estimation. These results do not contradict the earlier findings, but do not add to the evidence either. Tables can be found in the online Appendix. 
Table VI: Full time WORKIng WOMEN-BARgAining POWER EFFECTS With PREFERENCE DIFFERENCES

\begin{tabular}{|c|c|c|c|c|c|c|}
\hline \multirow[t]{2}{*}{ Bargaining power proxy $\varphi$ : } & \multicolumn{3}{|c|}{ Relative wage } & \multicolumn{3}{|c|}{ Relative income } \\
\hline & (1) & $(2)$ & $(3)$ & $(4)$ & $(5)$ & $(6)$ \\
\hline$\varphi \times\left(\alpha_{f}-\alpha_{m}\right)$ & $\begin{array}{c}1.9982 \\
(2.6446)\end{array}$ & $\begin{array}{c}2.9364 \\
(2.7618)\end{array}$ & $\begin{array}{c}3.3765 \\
(2.7731)\end{array}$ & $\begin{array}{c}3.2207^{* *} \\
(1.6357)\end{array}$ & $\begin{array}{c}3.6847^{* *} \\
(1.6914)\end{array}$ & $\begin{array}{c}3.6371^{* *} \\
(1.6879)\end{array}$ \\
\hline$\varphi$ & $\begin{array}{c}2.0670 \\
(2.2635)\end{array}$ & $\begin{array}{c}3.0803 \\
(3.0957)\end{array}$ & $\begin{array}{c}2.7639 \\
(3.0862)\end{array}$ & $\begin{array}{c}-0.9086 \\
(1.2864)\end{array}$ & $\begin{array}{l}-0.8367 \\
(1.3331)\end{array}$ & $\begin{array}{l}-0.6553 \\
(1.3281)\end{array}$ \\
\hline$\left(\alpha_{f}-\alpha_{m}\right)$ & $\begin{array}{c}-0.1794 \\
(1.3551)\end{array}$ & $\begin{array}{c}-0.8594 \\
(1.4165)\end{array}$ & $\begin{array}{c}-0.8038 \\
(1.4203)\end{array}$ & $\begin{array}{l}-0.5988 \\
(0.8410)\end{array}$ & $\begin{array}{l}-1.0260 \\
(0.8680)\end{array}$ & $\begin{array}{l}-0.7484 \\
(0.8641)\end{array}$ \\
\hline Household income & & $\begin{array}{c}0.0000 \\
(0.0002)\end{array}$ & $\begin{array}{l}-0.0000 \\
(0.0002)\end{array}$ & & $\begin{array}{l}-0.0001 \\
(0.0001)\end{array}$ & $\begin{array}{l}-0.0001 \\
(0.0001)\end{array}$ \\
\hline Sum of preferences & & & $\begin{array}{c}2.1619^{* * *} \\
(0.2731)\end{array}$ & & & $\begin{array}{c}2.1054^{* * *} \\
(0.2584)\end{array}$ \\
\hline Number of children fixed effects & Yes & Yes & Yes & Yes & Yes & Yes \\
\hline Control variables & & Yes & Yes & & Yes & Yes \\
\hline Observations & 4,778 & 4,636 & 4,636 & 5,111 & 4,964 & 4,964 \\
\hline
\end{tabular}

Notes: Coefficients from linear probability estimations with the dependent variable birth 12 to 23 months after the interview and multiplied by 100. The estimate of $\varphi \times\left(\alpha_{f}-\alpha_{m}\right)$ denotes the bargaining power effect. $\varphi$ is defined as the female's measure over the sum of both partners' measures. Robust standard errors from clustering on couples in parentheses, ${ }^{* *} \mathrm{p}<0.01,{ }^{* *} \mathrm{p}<0.05,{ }^{*} \mathrm{p}<0.1$. Number of child fixed effects include an indicator variable for each contemporaneous number of children. Additional control variables include age and age squared of both partners, an indicator variable for being a student, indicator variables for foreign citizenship and second-generation immigrants, indicator variables for federal states, and year fixed effects. Data source: SOEP. 


\section{Concluding Remarks}

In this paper, we derive a simple model of fertility decisions with heterogenous partners that has two main conclusions: female relative wage as a bargaining power determinant can have a negative relative cost effect and an ambiguous bargaining power effect on fertility. If her child preferences are stronger than her partner's, the bargaining power effect is positive. If her child preferences are weaker than her partner's, the bargaining power effect is negative. With concordant child preferences, the bargaining power effect is zero. We take this prediction to the data and find a differential bargaining power effect dependent on relative child preferences. The finding is robust to the inclusion of a number of control variables and different model specifications. We use restricted samples of childless couples and full-time working women to tackle concerns about self-selection. The results are consistent with the baseline estimates. Even if endogeneity cannot be ruled out completely as an alternative explanation, we have vast descriptive evidence in support of the theoretical predictions.

Using concordant and discordant preferences within couples is a new and alternative way of investigating bargaining processes in decision making about household public goods in general that could be used in different settings. Decisions about fertility, housing and other family investments are important subjects for policy makers and should be well understood. All policies that change the intra-household allocation of bargaining power, among them many policies that encourage female labor market participation, may have unintended consequences through the bargaining mechanism that should be accounted for in the design of welfare policies. However, conclusions should be interpreted with caution as we do not model or estimate possible offsetting effects of policies, e.g. through marriage market sorting. 
Acknowledgements: I would like to thank Ian Smith, Helmut Rainer, Thomas Siedler, Christian Thater, and two anonymous referees as well as the participants of the Econometric Society World Congress, the International Institute of Public Finance Congress, the European Society for Population Economics Conference, the International SOEP User Conference, and the Verein für Socialpolitik Annual Congress for their valuable comments and suggestions. 
Corresponding author: Timo Hener, Ifo Institute - Leibniz Institute for Economic Research at the University of Munich, Poschingerstr. 5, D-81679 Munich, Germany, contact: hener@ifo.de. 


\section{References}

Aizer, Anna (2010): "The Gender Wage Gap and Domestic Violence," The American Economic Review, Vol. 100, p. 1847-1859. [15]

Becker, Gary S. (1973): “A Theory of Marriage: Part I,” Journal of Political Economy, Vol. 81, p. 813-46. $[2]$

Blundell, Richard, Pierre-André Chiappori, And Costas Meghir (2005): "Collective Labor Supply with Children," Journal of Political Economy, Vol. 113, p. 1277-1306. [2]

Browning, Martin, François Bourguignon, Pierre-André Chiappori, And Valérie Lechene (1994): "Income and Outcomes: A Structural Model of Intrahousehold Allocation," Journal of Political Economy, Vol. 102, p. 1067-1096. [2,3]

Browning, Martin, Pierre-André Chiappori, And Valérie Lechene (2006): "Collective and Unitary Models: A Clarification," Review of Economics of the Household, Vol. 4, p. 5-14. [2,5]

Chiappori, Pierre-André (1988): "Rational Household Labor Supply," Econometrica, Vol. 56, p. 63-90. $[2]$ $[2]$

(1992): "Collective Labor Supply and Welfare," Journal of Political Economy, Vol. 100, p. 437-467.

Chiappori, Pierre-André And Ivar Ekeland (2006): "The Micro Economics of Group Behavior: General Characterization," Journal of Economic Theory, Vol. 130, p. 1-26. [2]

(2009): "The Microeconomics of Efficient Group Behavior: Identification," Econometrica, Vol. 77, p. $763-799 .[2]$

Datta Gupta, Nabanita And Leslie S. Stratton (2010): "Examining the Impact of Alternative Power Measures on Individual Time Use in American and Danish Couple Households," Review of Economics of the Household, Vol. 8, p. 325-343. [15,16]

Dolton, Peter J. And Gerald H. Makepeace (1986): "Sample Selection and Male-Female Earnings Differentials in the Graduate Labour Market," Oxford Economic Papers, Vol. 38, p. 317-341. [15]

Donni, Olivier (2009): "A Simple Approach to Investigate Intrahousehold Allocation of Private and Public Goods," The Review of Economics and Statistics, Vol. 91, p. 617-628. [2,4]

Duflo, Esther (2003): "Grandmothers and Granddaughters: Old-Age Pensions and Intrahousehold Allocation in South Africa," World Bank Economic Review, Vol. 27, p. 1-25. [4]

ERmisch, John AND Chiara Pronzato (2008): "Intra-Household Allocation of Resources: Inferences from Non-resident Fathers' Child Support Payments," Economic Journal, Vol. 118, p. 347-362. [3]

Heckman, James J. (1979): "Sample Selection Bias as a Specification Error," Econometrica, Vol. 47, p. 153-161. [15]

HoddinotT, John And Lawrence HadDad (1995): "Does Female Income Share Influence Household Expenditures? Evidence from Cote d'Ivoire," Oxford Bulletin of Economics and Statistics, Vol. 57, p. 77-96. $[4]$

IYIgun, Murat AND Randall P. WALsh (2007): "Endogenous Gender Power, Household Labor Supply and the Demographic Transition," Journal of Development Economics, Vol. 82, p. 138-155. [5]

Lundberg, Shelly J., Robert A. Pollak, And Terence J. Wales (1997): "Do Husbands and Wives Pool their Resources? Evidence from the United Kingdom Child Benefit," Journal of Human Resources, Vol. 32 , p. 463-480. [3,4]

Manser, Marilyn And Murray Brown (1980): "Marriage and Household Decision-making: A Bargaining Analysis," International Economic Review, Vol. 21, p. 31-44. [2]

Mazzocco, Maurizio (2007): "Household Intertemporal Behaviour: A Collective Characterization and a Test of Commitment," The Review of Economic Studies, Vol. 74, p. 857-895. [9]

McElroy, Marjorie B. And Mary Jean Horney (1981): "Nash-bargained Household Decisions: Toward a Generalization of the Theory of Demand," International Economic Review, Vol. 22, p. 333-349. [2]

Phipps, Shelley A. And Peter S. Burton (1998): "What's Mine Is Yours? The Influence of Male and Female Incomes on Patterns of Household Expenditure," Economica, Vol. 65, p. 599-613. [4]

Pollak, Robert A. (2005): "Bargaining Power in Marriage: Earnings, Wage Rates and Household Production," Working Paper 11239, National Bureau of Economic Research. [15] 
QIan, Nancy (2008): "Missing Women and the Price of Tea in China: The Effect of Sex-Specific Earnings on Sex Imbalance," Quarterly Journal of Economics, Vol. 123, p. 1251-1285. [4]

RAsul, Imran (2008): "Household Bargaining over Fertility: Theory and Evidence from Malaysia," Journal of Development Economics, Vol. 86, p. 215-241. [4]

Samuelson, Paul A. (1956): "Social Indifference Curves," Quarterly Journal of Economics, Vol. 70, p. $1-22 .[2]$

Schultz, T. Paul (1990): "Testing the Neoclassical Model of Family Labor Supply and Fertility," Journal of Human Resources, Vol. 25, p. 599-634. [4]

Thomas, Duncan (1990): "Intra-Household Resource Allocation: An Inferential Approach," Journal of Human Resources, Vol. 25, p. 635-664. [4]

_ (1994): "Like Father, like Son; Like Mother, like Daughter: Parental Resources and Child Height," Journal of Human Resources, Vol. 29, p. 950-988. [4]

Wagner, Gert G., Joachim R. Frick, AND Jürgen Schupp (2007): "The German Socio-Economic Panel Study (SOEP) - Scope, Evolution and Enhancements," Schmollers Jahrbuch : Journal of Applied Social Science Studies, Vol. 127, p. 139-169. [11] 